\title{
Testing for Adverse Selection and Moral Hazard in Consumer Loan Markets
}

\author{
Wendy Edelberg*
}

February 10, 2004

\begin{abstract}
This paper explores the significance of unobservable default risk in mortgage and automobile loan markets. I develop and estimate a two-period model that allows for heterogeneous forms of simultaneous adverse selection and moral hazard. Controlling for income levels, loan size and risk aversion, I find robust evidence of adverse selection, with borrowers self-selecting into contracts with varying interest rates and collateral requirements. For example, ex-post higher-risk borrowers pledge less collateral and pay higher interest rates. Moreover, there is strongly suggestive evidence of moral hazard such that collateral is used to induce a borrower's effort to avoid repayment problems. Thus, loan terms may have a feedback effect on behavior. Also, higher-risk borrowers are more difficult to induce into exerting effort, explaining the counter-intuitive result that higher-risk borrowers sometimes pay lower interest rates than observably lower-risk borrowers.
\end{abstract}

\footnotetext{
*Federal Reserve Board, email:Wendy.M.Edelberg@frb.gov. The views presented are solely those of the author and do not necessarily represent those of the Federal Reserve Board or its staff. I would like to thank Pierre-Andre Chiappori, Lars Hansen, Erik Hurst and Annette Vissing-Jorgensen, for their direction and advice. I also would like to thank the University of Chicago, the National Science Foundation and the Social Science Research Council for their financial support. Of course, all errors are my own.
} 


\section{Introduction}

The intertemporal interest rate, reflecting the cost of savings and borrowing to households, is one of the most important prices in economics models. Nearly all multi-period models of utility maximization take this interest rate as a parameter. The risk-free interest rate on savings is well grounded in the market for United States treasury instruments. On the other hand, using this same low interest rate for the cost of borrowing is clearly contrary to reality for most households. Models that endeavor to remedy this inconsistency often impose hard borrowing constraints, allowing households to borrow some fixed amount at this low interest rate or indeed nothing at all. This reveals the shortage of work in the area of how the market for consumer loans and borrowing interest rates are determined. While hard borrowing constraints may come into play for some households, casual observation shows that if the terms are favorable enough, lenders are willing to loan one more dollar to nearly anyone.

A better solution than hard borrowing constraints should incorporate the heterogeneity in loan terms among households. This heterogeneity will be due to both observables (for example, default risk) and unobservables that generate asymmetric information. While the contribution of default risk is taken up in another paper (Edelberg, 2003), the role of asymmetric information in interest rate heterogeneity is explored here. Numerous articles have been written exploring the theoretical implications of asymmetric information in credit markets, and countless models take this as an underlying assumption. However, this paper is one of the very few that investigates whether asymmetric information in credit markets can be documented empirically. I develop and estimate a two-period model with borrowers and lenders that allows for heterogeneous forms of simultaneous adverse selection and moral 
hazard. If lenders cannot contract on a borrower's effort to avoid repayment problems, contracts that satisfy an incentive compatible effort constraint may be optimal. Additionally, lenders may observe some risk characteristics, but there is the potential for remaining unobservable risk. As a result, contracts may be bound by a revelation constraint.

Data on mortgages and automobile loans from the Survey of Consumer Finances are used to test the model. Controlling for income levels, loan size and risk aversion, I find strong and robust evidence of adverse selection. Due to unobservable risk, borrowers self-select into contracts with varying interest rates and collateral requirements. For example, ex-post higher risk borrowers pledge less collateral and pay higher interest rates. These results are confirmed in a variety of empirical contexts. Additionally, I find evidence that is strongly suggestive of moral hazard such that collateral is used to induce higher effort. I also find that effort is more difficult to induce among higher risk borrowers versus lower risk borrowers. This difference explains the counter-intuitive result that higher risk borrowers sometimes pay lower interest rates.

The remainder of this paper is organized as follows. Section 2 briefly reviews the literature. Section 3 presents the model and discusses the equilibria that will be relevant for the empirical tests, while section 4 reviews the testable implications from this model. In section 5 the data are described and the empirical results are presented. Finally, section 6 demonstrates an additional test of asymmetric information that is less dependent on the structural model, and the results of that test are discussed. Section 7 summarizes the results and offers extensions for future research. 


\section{Literature Review}

The theoretical underpinnings of asymmetric information have been carefully investigated in a number of influential papers. For example, Akerlof (1970) describes the circumstances of the now well-known lemons problem where low quality goods can drive out high quality goods. Stiglitz and Weiss (1981) shows how asymmetric information can prevent a credit market from clearing, such that credit is rationed. In this paper, the authors assume that borrowers cannot pledge varying amounts of collateral when the interest rate is endogenous. Bester (1985) and Bester (1987) relax this assumption, showing that endogenously chosen levels of collateral may offset the problems of information asymmetry, and credit markets may clear.

Since Bester's articles were published, hundreds of articles exploring the implications of various contractual relationships in credit markets under asymmetric information have been written - many showing the implications of varying levels of collateral. For example, Igawa and Kanatas (1990) considers the moral hazard involved in the borrower's use of pledged collateral in the general environment of asymmetric information. They show that self-financing may be optimal for some borrowers given costly loan terms. Chan and Thakor (1987) discusses credit contracts with asymmetric information and potentially unlimited collateral. This paper shows that whether markets clear depends on which party receives the surplus, the bank's depositors or borrowers. As with most research on the subject, this paper only discusses moral hazard and adverse selection in turn.

One rare exception is Chassagnon and Chiappori (1996), which is discussed in more detail in later sections. Briefly, Chassagnon and Chiappori present a model with agents of 
different levels of unobservable risk as well as different degrees of moral hazard. The degree of moral hazard relates to how difficult it is to induce an agent into high effort. The requirements for existence and nature of possible equilibria are discussed, as well as the welfare implications of the introduction of adverse selection in addition to moral hazard. Another exception is Dubey and Geanakoplos (2001). Here, a model of borrowing is presented with potentially both adverse selection and moral hazard. Equilibrium is achieved by certain agents signaling creditworthiness by committing to borrowing constraints.

Compared to breadth of the theoretical literature, fewer papers have endeavored to document asymmetric information empirically. One area that has received attention is the vehicle market. For example, Bond (1982) finds no evidence of asymmetric information in the used truck market. In this case, the bad does not drive out the good. Bond suggests that the information problem is probably solved by warranties and costly collection of vehicle history. On the other hand, Genesove (1993) finds weak evidence of adverse selection in the wholesale used car market. While both new and used car dealers sell trade-ins on the wholesale market, he finds observationally equivalent trade-ins sold by new car dealers fetch a higher price. Used car dealers are thought to be keeping the best trade-ins to sell in the retail market.

Of course, the insurance market is another natural area for empirical research in asymmetric information. Chiappori and Salanié (2000) finds no evidence of adverse selection or moral hazard in the French market for automobile insurance. This paper presents a simple test for asymmetric information that does not rely on assumptions on preferences, market structure, or the nature of equilibria. In section 6 , this test is employed as a check of the results from the more structural methods. In contrast, Altman, Cutler and Zeckhauser (1998) identifies 
adverse selection in health insurance markets, investigating who chooses indemnity policies versus health maintenance organizations.

Perhaps the least explored area in light of the focus of the theoretical literature is the credit market. Among the few empirical papers in this field is Ausubel (1999) which finds evidence of adverse selection in the credit card market. This paper presents a remarkable data set with mass unsolicited offerings of credit cards with various terms to a randomized population. Calem and Mester (1995) presents evidence that credit card borrowers with high balances but low (unobservable) risk face high switching costs, so there is adverse selection when credit card companies lower rates to compete for borrowers.

This limited empirical literature in credit markets does not address whether collateral is used to offset asymmetric information. Given the preponderance of models that rely on collateral as a tool for sorting borrowers and inducing effort, this is a significant gap. This paper will endeavor to fill this gap, using a methodology similar to that used in the automobile and insurance research. In order to detect adverse selection, I first identify ex-post information that reveals characteristics that were hidden to one party at the time of the transaction. I then see if contracts sort on this information such that borrowers of differing risk reveal themselves ex-ante. An important and novel contribution this paper makes is presenting a test that can separately identify moral hazard as distinct from adverse selection. As is shown in the next section, this is done by modeling the costs and benefits of effort as a function of observable borrower characteristics. The exposition of the implications of this model follows Chassagnon and Chiappori (1996), which lays out the theory for a similar model of insurance. 


\section{The Model}

This two-period model includes two types of agents, borrowers and lenders. In period one, the borrower takes a loan for a fixed amount for an unspecified reason. In period two, the borrower either pays the lender principal plus interest or surrenders some amount of collateral in the case of default. Default occurs when the borrower does not have sufficient income to pay back the loan, such that contracts are perfectly enforceable. In period one, the lender loans out funds subject to a zero-profit condition (in expectation) with the cost of funds taken as given. In this sense, the supply of loanable funds is perfectly elastic. As will be clear below, the model focuses on the decision process for a borrower in period two. That the loan contract satisfies some reservation two-period utility for the borrower is assumed, though including reservation utility as a constraint in period one would not change the implications of the model; it would only reduce the set of possible contracts. Expected utility for agent $i$ in the period when the loan is due is as follows:

\section{Equation 1}

$$
E U_{i}=\left(1-\pi\left(e_{i}\right)\right) u\left(s_{i}\right)+\pi\left(e_{i}\right) u\left(f_{i}\right)-d_{i} e_{i}
$$

$$
\mathrm{s}_{\mathrm{i}}=\mathrm{W}+\mathrm{I}-\mathrm{R}_{\mathrm{i}} \text { and } \mathrm{f}_{\mathrm{i}}=\mathrm{W}-\mathrm{c}_{\mathrm{i}}
$$

where $u$ is increasing and strictly concave. $W$ is wealth which is exempt in bankruptcy proceedings, while $c$ is collateral pledged out of exempt wealth. $\pi_{\mathrm{i}}$ is the probability of default for individual $i$, which is a function of effort $e$. $e$ can only take on the values 1 and $0 .{ }^{1}$ With probability $(1-\pi)$ the individual makes income $I$ and is able to pay back the loan. $d_{i}$ is the cost of effort, which is assumed linear and separable with respect to consumption but allowed to vary by individual.

\footnotetext{
${ }^{1}$ One benefit of discontinuous effort is that this model should not be subject to the Mirrlees (1999) critique. Under moral hazard, the first-best equilibrium (in this case zero collateral with high effort) should not be attainable under many plausible values of $\pi$ and $d$.
} 
Contracts are fully characterized by the total loan payment (interest plus principal), $R_{i}$, and $c_{i}$, such that contract $x_{i}=\left(R_{i}, c_{i}\right)$. When $e_{i}=1, \pi_{i}=P_{i}$, and when $e_{i}=0, \pi_{i}=Q_{i}$, where $Q_{i}>P_{i}$ so that zero effort means a higher chance of default. Lenders are either risk-neutral or can diversify sufficiently so that they act risk neutral. As a result, they simply maximize the expected payoff from each contract. Contracts with expected negative earnings are not issued, and competition ensures that profits are zero. ${ }^{2}$ The zero profit condition for $x_{i}$ is as follows:

\section{Equation $2 \quad\left(1-\pi_{\mathrm{i}}\left(\mathrm{e}_{\mathrm{i}}\right)\right) \mathrm{R}_{\mathrm{i}}+\pi_{\mathrm{i}}\left(\mathrm{e}_{\mathrm{i}}\right) \mathrm{c}_{\mathrm{i}}-\mathrm{F}=0$}

where $F$ is the cost of issuing the loan (assumed not to vary by individual). $F$ takes into account the cost of funds to the lender. I assume lenders cover these costs on average, and lenders have no asymmetric information issues of their own, so this cost of funds does not vary with the lenders' portfolios.

Note that both effort and thus default probability may be a function of the contract in the case of asymmetric information. To this end, probabilities will sometimes be denoted $\pi_{i}\left(x_{i}\right)$. If lenders cannot contract on effort, this will lead to a case of moral hazard. Given the necessity of paying $R$ to the lender in the successful state, the returns to effort are reduced for the borrower. Lenders may find it profitable to issue contracts that help to induce higher effort. ${ }^{3}$ Whether or not this is profitable depends on the magnitude $Q_{i}-P_{i}$ which essentially measures the effectiveness of high effort. Note that I assume that the ex-post state is observable to both

\footnotetext{
${ }^{2}$ The implicit assumption is that no contract is issued with $R_{i}>I$.

${ }^{3}$ The notion of profitability is useful despite the lender's zero-profit condition. If lenders are making zeroprofits while borrowers' utility is not maximized, a lender can offer a different contract that increases borrower utility and makes the lender a profit. Assuming perfect competition, other lenders should follow suit until borrower utility is maximized, and lenders' profit are zero.
} 
the lender and borrower, so that there is no issue of honesty in reporting whether income $I$ has been obtained.

Adverse selection may come into play if lenders cannot distinguish between types $i$ and $j$, for example. Lenders may find it profitable to issue a menu of contracts such that borrowers sort themselves and thereby reveal their type. In this sense, risk may be endogenous to the contract.

While this set-up is sufficiently flexible to permit us to broadly test for moral hazard and adverse selection with important allowances for heterogeneity, it makes a number of simplifying assumptions. Namely, all individuals have the same utility function, the same wealth, and the same potential for income in the successful state. Furthermore, the probability structure is greatly simplified so that there are only two possible states of the world, one where $I \geq R_{i}$ and the loan is repaid in full, and one where $I=0$, and the lender receives only pledged collateral. Despite these simplifications, characterizing the equilibrium is by no means trivial, and, as will be shown below, a broad range of results are possible.

Agents are indexed by levels of riskiness. The nature of "riskiness" is defined as follows:

\section{Equation $3 \quad P_{i}>P_{j}$ and $Q_{i}>Q_{j}$, for $i>j$.}

Note that I allow for the possibility that $Q_{i}>P_{j}$ for $i<j$ such that a less risky person expending no effort can have a higher probability of default than a more risky person who is expending effort. As in Chassagnon and Chiappori (1996) I rule out the non-generic case where $Q_{i}=P_{j}$ to avoid peculiar equilibria. 


\section{a. Moral Hazard}

If lenders cannot contract on effort, contracts may be set to induce higher effort. This is possible if a contract $x_{i}$ satisfies an incentive compatibility constraint (ICC):

Equation $4 \quad\left(1-\mathrm{P}_{\mathrm{i}}\right) \mathrm{u}\left(\mathrm{s}_{\mathrm{i}}\right)+\mathrm{P}_{\mathrm{i}} \mathrm{u}\left(\mathrm{f}_{\mathrm{i}}\right)-\mathrm{d}_{\mathrm{i}} \geq\left(1-\mathrm{Q}_{\mathrm{i}}\right) \mathrm{u}\left(\mathrm{s}_{\mathrm{i}}\right)+\mathrm{Q}_{\mathrm{i}} \mathrm{u}\left(\mathrm{f}_{\mathrm{i}}\right)$

This can be simplified to:

Equation $5 \quad \mathrm{u}\left(\mathrm{s}_{\mathrm{i}}\right)-\mathrm{u}\left(\mathrm{f}_{\mathrm{i}}\right) \geq \frac{\mathrm{d}_{\mathrm{i}}}{\mathrm{Q}_{\mathrm{i}}-P_{\mathrm{i}}}=\theta_{\mathrm{i}}$

The set of incentive compatible contracts, $\varepsilon_{i}$ has the frontier:

Equation $6 u\left(\mathrm{~W}+\mathrm{I}-\mathrm{R}_{\mathrm{i}}\right)-\mathrm{u}\left(\mathrm{W}-\mathrm{c}_{\mathrm{i}}\right)=\theta_{\mathrm{i}}$

In order to ensure that there are indeed contracts in $\varepsilon_{i}$, I assume that high effort is optimal if there is no loan such that ${ }^{4}$

Equation $7 \quad \mathrm{u}(\mathrm{W}+\mathrm{I})-\mathrm{u}(\mathrm{W}) \geq \theta_{\mathrm{i}}$

Figure 1 shows the ICC and the zero-profit lines for two borrowers with different $\pi$ 's and $\theta$ 's. The figure shows the case where $\theta_{1}>\theta_{2}$, or in other words, where borrower 1 is more difficult to induce into high effort than borrower 2. Note that the zero-profit lines become flatter as they cross the ICC frontier, as effort goes from 1 to 0 .

\section{b. Adverse Selection}

If lenders cannot distinguish between types, contracts will have to fulfill a revelation constraint for separating equilibria. The revelation constraint, in a slightly simplified form, is as follows:

${ }^{4}$ While equation 7 holds, we do not discuss the uninteresting case where $\theta_{\mathrm{i}}$ is so low that effort is optimal for a wide range of plausible values for $x_{i}$ despite the potential for moral hazard. In any case, such a low $\theta_{\mathrm{i}}$ has testable implications that will be ruled out in the empirical section below. 
Equation $8 \quad u\left(s_{i}\right)+\pi\left(x_{i}\right)\left(u\left(f_{i}\right)-u\left(s_{i}\right)\right) \geq u\left(s_{j}\right)+\pi\left(x_{j}\right)\left(u\left(f_{j}\right)-u\left(s_{j}\right)\right)-d_{i}\left(e_{i}\left(x_{j}\right)-e_{i}\left(x_{i}\right)\right)$

where $\pi$ and $e$ are still a function of contract choice. In other words, lenders will offer a menu of contracts, and agents will optimally sort themselves into contracts that reveal their risk type. Figure 2 shows the familiar case of separating equilibria with adverse selection and no moral hazard for two borrowers. Note that in this case the revelation constraint is binding for the riskier agent, agent 2, and not for agent 1. Figure 2 includes indifferences curves for the 2 borrowers. Notice that the higher risk borrower has a flatter indifference curve.

\section{c. Moral Hazard and Adverse Selection}

In the discussion below, I reduce the number of possible equilibria in this case by limiting the set of parameter values. This facilitates the empirical tests. First, assume there are four types of agents, $i=1,2,3$ or 4 . Agent 4 is riskier than agent 3, 3 is riskier than 2 , and 2 is riskier than 1. Additionally, assume a lender can only distinguish between two categories of riskiness $H$ and $L$. Category $L$ contains type $i=1,2$, and category $H$ contains type $i=3,4$. The identifying assumption necessary to obtain clear predictions from the model is that moral hazard is equal within a category where $\theta_{1}=\theta_{2}$ and $\theta_{3}=\theta_{4}$. Thus, there is potential adverse selection within a category (since characteristics that distinguish borrowers within categories are unobservable) and potentially different degrees of moral hazard across categories. More will be said regarding the justification for this identification strategy in section 5. Possible equilibria will have the same properties across categories, so the discussion can be limited to one category.

Chassagnon and Chiappori (1996) shows that indifference curves of two agents cross only once if $\theta_{i}=\theta_{j}$. This is true in this case as the effort frontier is identical for agents within $H$ 
and $L$ Note that with single crossing $x_{2}$ and $x_{4}$ are pinned down by where the zero-profit line intersects the effort frontier if effort is induced. If effort is not induced, the contract is located where the zero-profit line intersects the $R$ axis. With this in mind, I employ the same concept of equilibrium used in Rothschild and Stiglitz (1976):

A pair of contracts $x_{i}=\left(R_{i}, c_{i}\right)$ and $x_{j}=\left(R_{j}, c_{j}\right)$ for $i \neq j$ is an equilibrium if the following two conditions hold true:

1) no contract in the equilibrium pair makes negative expected profits

2) no new contract can be offered and make positive profits

When equilibria exist, they must be separating. Of course, in the presence of adverse selection and moral hazard, it is not necessary that both agents of single type be induced into high effort. For example, while it is true that under single crossing high-risk agents within a type receive the contract that would be optimal under moral hazard with no adverse selection, this pure moral hazard contract may not induce effort. To be sure, even with the assurance of the single crossing of indifference curves, the possible separating equilibria are quite numerous, and the reader is invited to read Chassagnon and Chiappori (1996) to get a more detailed account of these equilibria in an insurance context. Here, I concentrate on the case where effort is induced and the revelation constraint is binding for the high-risk agent because this is empirically relevant.

An example of separating equilibria that induce effort is in Figure 3. Note that the indifference curves stop at the effort frontier. Below the effort frontier, indifference curves become flatter as a greater reduction in $r$ is necessary to offset an increase in $c$, as default is more likely. For readability, these indifference curves are not shown. 


\section{Testable Results}

Considering types $H$ and $L$ (each containing both relatively high and low risk borrowers) rather than dividing the agents into only two risk groups allows us to better mimic the decision process of the lender. Lenders do employ observable information when issuing loans; borrowers risk profiles are not completely hidden. But, some heterogeneity in risk does remain hidden, and this may cause some level of adverse selection for lenders - a possibility captured in this framework. Lenders use observable information to put borrowers into categories $H$ and $L$, but the more subtle risk distinctions within categories must be revealed through contract choice. One benefit of this approach is that I will be able to draw conclusions regarding the level of moral hazard across $H$ and $L$.

Case 1: If there is no moral hazard or lenders optimally offer contracts that do not induce effort, ex-post high risk borrowers (agents 2 and 4) should receive $x_{i}=\left(R_{i}, 0\right)$ as this maximizes utility. Thus, a finding of $c>0$ for all borrowers is evidence of moral hazard as well as evidence that contracts are set to induce effort.

Figure 2 shows the case with no moral hazard or zero optimal effort (under second-best contracts with adverse selection). Under this scenario with these 4 agents, $c_{2}=0$ and $c_{4}=0$. If $c>0$ for all contracts, it must be the case that all contracts are on or above $\varepsilon_{i}$ for all $I$. This testable implication is not dependent on the identifying assumption that cost of effort is equal within observable risk groups.

Case 2: $R_{2}>R_{4}$, a certainly counter-intuitive result, is evidence that $\theta_{H}>\theta_{L}$. While $R_{2}<R_{4}$ may also be true when $\theta_{H}>\theta_{L}, R_{2}>R_{4}$ will not occur if $\theta_{H}<\theta_{L}$. As in Case $1, R_{2}>R_{4}$ is evidence of moral hazard as well as evidence that contracts are set to induce effort. 
If it is easier to induce effort among group $L$ borrowers, or $\theta_{H}>\theta_{L}$, the effort frontier for $L$ borrowers will be lower than for $H$ borrowers. This will have implications for the relationship between the contracts offered to the riskier $H$ and $L$ borrowers. Again, if effort is induced, agents 2 and 4 will select the contract where their respective zero-profit conditions and $\varepsilon^{\prime} \mathrm{s}$ intersect. In Figure 4, contract $x_{2}$ is selected by the type 2 borrowers. Two possible contracts for type 4 borrowers are shown: $x_{4}$ and $X_{4}$ which depend on the location of this intersection.

Note that $x_{2}(r)<X_{4}(r)$, but $x_{2}(r)>x_{4}(r)$. Finding that type 2 borrowers pay lower interest rates than type 4 borrowers may not be evidence that $\theta_{H}>\theta_{L}$, since this will also occur when $\theta_{H}<\theta_{L}$. However, $r_{2}>r_{4}$ if and only if $\theta_{H}>\theta_{L}$ when all borrowers exert high effort. This testable implication is also not dependent on the identifying assumption of equal cost of effort within risk groups. The cost of effort is certainly allowed to be different for agents 2 and 4 , so restrictions on $\theta$ are not playing a role here.

Case 3: Adverse selection is present if ex-post information (that was unobservable to the lender) that helps distinguish between borrowers within categories reveals: $R_{2}>R_{1}, R_{4}>R_{3}$, $c_{2}<c_{1}$, and $c_{4}<c_{3}$.

If contracts are not subject to adverse selection (perhaps if lenders can perfectly predict any useful unobservable information), the revelation constraint is not binding for any agent. Figure 5 shows the case with moral hazard but no adverse selection.

Note that in Figure 5, $R_{2}>R_{1}$ and $c_{2}>c_{1}$. An empirical finding of this nature would be evidence of no adverse selection (on the condition that the identifying restrictions are not driving the results). Again, the identification restriction of equal cost of effort within $H$ and $L$ is not necessary to reject adverse selection under these conditions. Regardless of the cost of effort, 
if $R_{2}>R_{1}$ and $c_{2}>c_{1}$, contract 1 brings higher utility to any borrower over contract 2 . If adverse selection was a potential problem, these contracts could not both be offered as all borrowers would select contract 1 .

In contrast, the identification restriction is necessary to claim the reverse: a finding of $R_{2}>R_{1}$ and $c_{2}<c_{1}$ is positive evidence of adverse selection. $\theta_{1} \neq \theta_{2}$ can also account for this result (specifically, $\theta_{1}>\theta_{2}$ ). However, in this case we could appeal to the weaker assumption of an increasing or decreasing relationship between the cost of effort and risk class. With the finding of $\theta_{1}>\theta_{2}$, this would imply $\theta_{1} \geq \theta_{2} \geq \theta_{3} \geq \theta_{4}$. In this case we must see that $R_{4} \geq R_{3} \geq R_{2} \geq R_{1}$ for the case where all contracts are the result of only moral hazard with no possible adverse selection. This is violated in the empirical results.

If strategic default is plays a significant role in consumer loan markets, lenders may set contract terms in order to make it less likely. Strategic default occurs when a borrower has the financial ability to pay back a loan, but chooses to default nonetheless. This may be financially beneficial if, either, borrowers have limited liability, so that income and assets are protected, or lenders do not pursue borrower's income or assets in default.

Increasing collateral requirements may make strategic default less attractive if collateral is easy to seize in default. Conversely, higher interest rates make loan repayment less appealing to borrowers and might increase the likelihood of strategic default. If lenders view different types of borrowers more or less amenable to strategic default, collateral requirements and interest rates may vary among households regardless of adverse selection and moral hazard.

Empirically, strategic default does not appear to play a significant role in consumer loan markets (for example. see Jones (1993)). Briefly, lenders have a number of mechanisms for 
punishing defaulting borrowers, regardless of the level of collateral pledged. Defaults are reported to credit agencies, making future borrowing more difficult and costly. Lenders can pursue deficiency judgments against delinquent borrowers, demanding any future income above subsistence levels and many household assets. Finally, while obtaining deficiency judgments is costly, seizing even pledged collateral is also costly. Generally, lenders use threats of seizure to persuade a borrower to pay rather than actual seizure. In pledging collateral a household gives up any protection of that asset in bankruptcy. This makes bankruptcy more costly and increases the incentive for a household to reduce $\pi{ }^{5}$ This brings the focus back to a borrower's cost of effort to influence $\pi$, and away from the lure of strategic default.

\section{Empirical Results}

\section{a. Data}

The Federal Reserve Board administered the triennial Survey of Consumer Finances with the cooperation of the Department of the Treasury in 1983, 1989, 1992, 1995 and 1998. Unfortunately, the 1986 survey used a different methodology from the other surveys, so it must be excluded from this analysis. The SCF attempts to provide a picture of the distribution of assets, liabilities, income, and use of financial institutions and instruments across households in the United States. Numbers of families surveyed were as follows: $1983-4,103,1989-3,143$, $1992-3,906,1995-4,299$, and 1998 - 4,305 for a total of 19,756. In this paper, agent, family, and household will be used interchangeably, but the definition of the survey unit is closest to the U.S. Bureau of the Census definition of the term "household". A notable feature of the

\footnotetext{
${ }^{5}$ Like strategic default, strategic bankruptcy also does not appear to play a significant role. See Sullivan et al (2000) for a compelling evidence of this finding.
} 
survey is that it oversamples relatively wealthy households. This is important to get an accurate representation of wealth holdings in the U.S. since the wealth distribution is so skewed. The Federal Reserve Board provides sampling weights that reweight the survey population to correspond the U.S. population both by geographic area and, more closely, by income distribution. These weights are used in all measures of first and second moments using the SCF data. ${ }^{6}$ I follow the Board in using the consumer price index to deflate the nominal numbers to real numbers. All dollar amounts are reported in 1998 dollars.

The SCF contains data on a broad array of non-collateralized and collateralized loans and their interest rates. All loans considered here are active in the month of the survey. In addition, if households have multiple loans in a category, the highest interest rate is used in the analysis, and the dollar amounts relevant for the multiple loans are summed. For example, it is not uncommon for households to have multiple automobile loans at different interest rates. All data on automobile loans are aggregated to get one auto loan at the highest interest rate. This interest rate can then be thought of as the marginal rate at which a household could borrow one additional dollar to finance an automobile. If one sums all the automobile loans for ease of estimation, this is clearly the relevant interest rate to consider.

Table 1 gives an indication of the extent of heterogeneity in interest rates. Rates are taken from loans with origination years between 1995 and 1998.

\footnotetext{
${ }^{6}$ Deaton (1998) makes a convincing argument that weights should not be included in models when parameters do not vary across the population. In contrast, in models using SCF data, we assume that coefficients are constant across the population.
} 


\section{b. Identification Strategy}

The empirical work focuses on first mortgage loans and automobile loans. The basic strategy will be to divide borrowers into groups based on ex-ante observable and unobservable information. Then, I can compare average interest rates and collateral requirements across groups and test for asymmetric information using the cases in section 4. First, households are sorted into $H$ and $L$ based on some measure of risk that is observable to the lender. Households are further divided into 1,2,3 and 4 based on data that is only observable after the loan is issued.

This unobservable data reflects some hidden information known only to the borrower when the loan is issued. For example, the borrower may have a better prediction of future shocks to financial security than the lender. The nature of this uncertainty might be the possibility of a change in job or marriage status or simply an overall change in wealth. The basic identifying restriction is that the costs and effectiveness of effort are only a function of observables. For example, it is intuitive that $\theta$ should be related to observables such as income, education and age, though one can make different arguments regarding the nature of this relationship. The benefit of effort may be higher for an agent with low income, given a kind of diminishing returns to effort scenario - effort loses its effectiveness as income reaches the upper end of the distribution and potential income growth lessens. On the other hand, those with higher income may have more potential for upward mobility given the different nature of their occupations, so that effort on the job has a far greater payoff. In any case, assuming that $\theta$ is not a function of future shocks and rather is a function of observables, a reasonable conclusion is that $\theta_{1}=\theta_{2}$ and $\theta_{3}=\theta_{4}$, and hence $\theta$ is equal within risk categories. 
As a result, effort is equal within groups $L$ and $H$, and, for example, 2 will be riskier, or more likely to default, than 1 . Looking at this another way, those in $L$ who default are more likely to be 2's than 1 's, and likewise for $H$ 's. I assign all $H$ borrowers who default to type 4 and all $L$ borrowers who default to type 2. (Those who do not default are 1's and 3's.) Of course, this will mean that some borrowers will be mislabeled. For example, some defaulting $L$ 's will be unlucky 1's mislabeled as 2's. As a result, differences among the four types will be obscured, and any findings of significant results will be that much more remarkable. Empirically, agents will be assigned type by a late payment indicator.

Borrowers will be categorized as $H$ and $L$ based on their predicted probability to be at least two months late on a loan payment. The SCF contains an indicator variable of whether a household has been over two months late on payments in the past year, so this actual variable would be unobservable to any lender issuing a loan less recently than when the late payments were made. This indicator can be viewed as containing unobservable data. On the other hand, it can also be used to come up with an empirical model of predicted probabilities of being late that is based on information observable to the lender.

The late payment indicator is predicted in a selection model using characteristics chosen in a large part based on the bankruptcy literature such as Fay et al (1998). To briefly discuss the methodology, since the SCF only contains data on delinquency for households with positive debt, I must account for possible selection bias. A number of variables are used to predict whether a household holds debt, many of which are hidden from any lender predicting default risk. These include attitudinal variables that measure a respondent's level of acceptance of debt. The portion of the selection model that predicts debt holding is not discussed here, as it is not 
the focus of this analysis. This methodology for predicting risk of delinquency, the choice of explanatory variables, and the full model results are discussed in depth in Edelberg (2003). I include year interaction terms for coefficients that change significantly over time. Results of the late payment probit portion of the selection model are reported in Table 2.

A few highlights from the probit are discussed here. The probability of being late increases from 1983 to 1989 , decreases through 1995, falling below its 1983 level, and then increases a little. As age increases, the contribution to the probability of being late first increases up to age 29 and then falls. The contribution eventually turns negative at an age of 58 . Home ownership negatively predicts delinquencies, with its effect generally increasing over time, when significant. The variable reflecting a high ratio of unsecured debt to income is also helpful in predicting late payment (and the sign is as expected). Once the probability of late payments is estimated for each household, these probabilities can be used to measure this type of important observable default risk.

Predicted probabilities of late payments for the entire SCF sample are reported in Table 3. While over the five years of data, $12 \%$ of the respondents have been late, in the predicted values the mean probability of making late payments is $9 \%$. These values reveal that late payments are indeed not a negligible problem.

\section{c. Conditional mean results}

Before the results in Table 4 are discussed, a few complicating issues need to be considered. The model above assumes equal cost of funds and loan amounts across agent type. The cost of funds is kept roughly constant by limiting the analysis to loans originated from 
1995 to $1998 .^{7}$ Dealing with the equal loan size assumption is more complicated. The model gives predictions regarding the dollar value of collateral given a certain loan amount. For two agents with equal loan size, the ratio of the loan size to the size of the asset used as collateral can be equivalently compared. I define this ratio, commonly referred to as the loan-to-value ratio, as $\rho$. An agent with more collateral for a loan will also have a lower $\rho$. The benefit of this measure $\rho$ is that I can compare households with different loan sizes. Letting loan size vary, an agent that must offer more than a proportional increase in collateral for his larger loan will have a lower $\rho$ than an agent with less respective collateral. Similarly, rather than measuring the dollar amount of principal plus interest that a borrower must pay given a certain loan size, I measure the interest rate in percentage points, $r$. Unfortunately, $\rho$ and $r$ may vary as a result of loan size rather than due to asymmetric information. Some nonparametric checks are done to test for this, but this issue is further addressed later in the regressions in section $\mathrm{d}$.

The SCF contains data for mortgages on the current home value and the current loan balance. $^{8}$ These data are used to construct $\rho$. Limiting the origination years to 1995 to 1998 has an added benefit besides keeping banks' costs of funds are relatively stable. Loans are new enough that early payment of principal is not playing a big role in calculations of $\rho$. For automobiles, varying depreciation is an important factor in assessing value after purchase. To avoid this complication (without having data on the vehicle's value at purchase), only automobile loans originated in the survey years 1995 and 1998 are considered. In order to

\footnotetext{
${ }^{7}$ While other year windows certainly could have been used, these years offer the largest bin sizes for the non-parametric tests. The results are robust but less precise for other years with substantial (but smaller) bin sizes.

${ }^{8}$ While it would be ideal to calculate $\rho$ for original loan amounts and home value at the time the loan was issued, these data are unavailable. The SCF does contain data on the home purchase price, but due to refinancing in the 1990s this too often not the home value when the loan is issued. Limiting the sample to those who did not refinance and calculating $\rho$ as the ratio of the original loan size to the concurrent home value produces very similar point estimates with very few observations for some bins.
} 
increase bin sizes, results are also calculated across all survey years, and point estimates are robust. 9

Note that $\rho$ 's in Table 4 are all below 1, suggesting the all the loans are overcollateralized. This does not imply, however, that lenders are fully insured against default risk. While there is only incomplete research on loan recovery in default, estimates for residential mortgages are that only $50 \%$ to $70 \%$ of the loan is recovered in default. The clearest reasons for this are that foreclosed homes generally sell for substantially below market value and selling costs are high for the lender. There is even less empirical work in this area for automobile loans, but it is intuitive that repossessed automobiles sold at public auction by a middleman recoup less than the market price for the lender.

In the model, loan maturities are also assumed to be equal across loans. Since loan maturities can vary widely for first mortgages, a robustness check is done limiting the sample to those with 30-year mortgages, and point estimates are consistent. Further limitations on whether the interest rate is fixed also produce generally similar point estimates. On the other hand, automobile loan maturities vary much less, and so all automobile loans are included. ${ }^{10}$ Finally, income potential and collateralizable wealth are also assumed constant across borrowers. By only including borrowers within given asset or income quantiles, the bin sizes

\footnotetext{
${ }^{9}$ In general, dividing borrowers into our 4 groups appears to be a reasonable method. We should expect to see that variance is smaller within groups than overall if these groups truly represent different types of borrowers in reality. Variance in $r$ and $\rho$ within the four types is generally comparable and often smaller than variance is overall. For example, $\rho$ for automobiles has an overall standard deviation of 12.20 and an average standard deviation of 10.63 across the four types. A less encouraging example is automobile rates which have an overall standard deviation of 4.05 and an average standard deviation of 4.39 across the four types. For first mortgages, overall standard deviation for $\rho$ is 2.86, while the average across the four groups is 1.52 . Mortgage rates' standard deviation is 1.16 , while the average across the groups is 1.26. Many other methods of using this observable and unobservable information were tried with no great advantage in reductions in variance.

${ }^{10}$ For example, $80 \%$ of families with automobile loans have loan maturities between 3 and 5 years.
} 
are reduced to such an extent that standard errors render nearly all the results inconclusive. However, in almost all cases, conditioning on asset or income levels does not change the qualitative relationships of the point estimates, regardless of which levels are included. This evidence suggests that, in the case of asset quantiles, constraints on collateralizable wealth are not driving the results. Additionally, conditionally on loan size quantiles also does change the qualitative results overall.

\section{i. Moral Hazard}

The conditional mean results are reported in Table 4. Case 1 states that a finding of $c>0$ for all borrowers is evidence of moral hazard as well as evidence that contracts are set to induce effort. Of course, this is true only in a world where lenders can offer a menu of both collateralized and non-collateralized loans. This analysis is limited to collateralized loans. As a result, a finding of $c>0$ for all borrowers is much less meaningful. For mortgages, one could argue that the near complete absence of a zero collateral method of financing a home purchase is evidence of moral hazard (except for the very rare agent who could borrow upwards of $\$ 100,000$ on a line of credit or a credit card).

Automobile loans make for a more difficult argument, since more households could fund a car purchase with a non-collateralized loan, but these loans will not be in the sample. In the case of no moral hazard, even the riskiest person with an automobile loan may pledge collateral to distinguish himself from an even riskier person who would fund a car purchase with a line of credit or cash advance on a credit card. So, for both loan types, it is possible that everyone pledges collateral even in the case that the effort frontier is irrelevant. However, one testable result remains. In the case that $\varepsilon_{i}$ is irrelevant, $x_{4}$ and $x_{2}$ may fall below $\varepsilon_{i}$. Indeed, given 
that the only role of collateral would be to distinguish lower risk borrowers, the lowest possible value of collateral that serves this purpose would maximize borrower utility. One would expect to see values of $\rho$ very close to one in this case. On the other hand, finding that $x_{4}$ and $x_{2}$ (indeed all the contracts) lie on or above the effort frontier strongly suggests that $\varepsilon_{i}$ is binding.

Equation 7 assures that $x_{i}=\left(R_{i}, R_{i}\right)$ is above $\varepsilon_{i}$ since utility is concave. In other words, if $c_{i} \geq R_{i}, x_{i}$ is incentive compatible. If $R_{i}$ is roughly the remaining loan balance paid back with interest, then

Equation $9 \quad \mathrm{c}_{\mathrm{i}} \geq \mathrm{R}_{\mathrm{i}}$ if and only if $1 \geq\left(1+\mathrm{r}_{\mathrm{i}}\right) \rho_{\mathrm{i}}$

Note that this is true in nearly all cases, except for $x_{4}$ and $x_{2}$ for automobile loans. ${ }^{11}$ For automobile's $x_{2}, 1 \geq\left(1+\mathrm{r}_{\mathrm{i}}\right) \rho_{\mathrm{i}}$ cannot be rejected, though neither can $\rho_{\mathrm{i}}=1$. Still, if moral hazard played no role in mortgage or automobile loans, one should not expect to see nearly all contracts lying above the effort frontier. This result is robust to allowing up to ten observable risk categories for automobile loans and five for mortgage loans. (Having more than five observable risk categories for mortgages renders the majority of the bin sizes below 5.)

Note that for both loans, the counter-intuitive result emerges that $r_{3}<r_{2}$ despite type 3's being higher risk borrowers (the difference is significant for mortgages). Indeed, for first mortgages, even $r_{4}<r_{2}$. While the former result is evidence of moral hazard under most specifications of utility (the exception being when agent 4 has a very steep indifference curve), the later is only possible in this model if type $H$ have higher moral hazard than type $L$, and the effort frontiers bind. As case 2 shows, it is more difficult to induce higher risk borrowers than lower risk borrowers into expending effort. The means for collateral are consistent with $\theta_{H}>\theta_{L}$

\footnotetext{
${ }^{11}$ Conditioning on income and loan size quantiles reverses the results for $x_{4}$ and $x_{2}$ such that $1 \geq\left(1+\mathrm{r}_{\mathrm{i}}\right) \rho_{\mathrm{i}}$
} 
for mortgages given that $\rho_{4}<\rho_{2}$. Remarkably, for mortgages the null hypothesis that $r_{4}=r_{2}$ can be rejected with a p-value of .03 , and we will see that this result is significant under the regression results as well. For automobile loans, the null hypotheses that $r_{4}=r_{2}$ and $\rho_{4}=\rho_{2}$ cannot be rejected.

These interest rate results are not due to survivor bias. In general, riskier borrowers will default earlier on loans than less risky borrowers. As a result, older loans in the data will be held by less risky borrowers. If interest rates are decreasing over time, lower interest rates may be associated with riskier borrowers. Limiting the sample to 1993 to 1995, when many consumer loan interest rates were actually increasing, should bias the results in the other direction: riskier borrowers should have higher interest rates, not lower. Indeed, the results are unchanged, though standard errors are larger due to a substantial reduction in sample size.

\section{ii. Adverse Selection}

For both loans, types 2 and 4 have a higher $r$ and higher $\rho$ than type 1 and 3, respectively. As case 3 explains, this is evidence of adverse selection in both the mortgage and automobile loan markets, under the identifying assumptions. ${ }^{12}$ Unlike the interest rate evidence for moral hazard, these interest rate relationships could not be due to survivor bias, since the interest rates are generally falling over the sample. In any case however, there should be no evidence that $\rho_{1} \leq \rho_{2}$ and $\rho_{3} \leq \rho_{4}$. Indeed, if survivor bias is somehow driving the results and not adverse selection, then lenders should be able to observe or successfully predict the risk that is

\footnotetext{
${ }^{12}$ While the case is complicated to make, this is also evidence of adverse selection under the weaker assumption of cost of effort decreasing with risk, though this assumption is not supported by the empirical results above. If $\theta$ varies unsystematically with risk, all that can be said is that the null hypothesis of no adverse selection cannot be rejected.
} 
defined here as unobservable. In that case, contracts should be determined as in Figure 5, and the collateral results should be $\rho_{1} \geq \rho_{2}$ and $\rho_{3} \geq \rho_{4}$.

These results are extremely robust. Conditioning on income, asset or loan size quantiles does not reverse the relationships in nearly all cases. (Where relationships are reversed, bin sizes are so small and standard errors are so big as to render the results meaningless.) Additionally, increasing the number of risk categories also does not change the basic result that ex-post higher risk borrowers pay higher interest rates and pledge less collateral than ex-post lower risk borrowers.

The differences for $r$ are significant for low risk group $L$ for both mortgages and automobile loans. All the differences for $\rho$ are significant except for mortgage's group $H$. Section ii shows results of one-sided joint hypothesis tests to determine if the null hypothesis of no adverse selection across risk groups can be rejected. These results for the conditional mean model are included in results from the regression models of the next section. In all cases the null hypothesis of no adverse selection in the conditional mean estimates can be rejected at a confidence level of $95 \%$ (though one case is very slightly lower than $95 \%$ ).

\section{d. Regression Results}

Using a regression approach allows for easier conditioning on loan size. Also, it can be checked that the more flexible conditional mean results are robust to an alternative method of conditioning on income and asset level. I use reduced form equations for $r$ and $\rho$. The interest rate equation is: 
Equation $10 \quad \mathrm{r}_{\mathrm{i}}=\beta_{1}+\sum_{\mathrm{d}=2}^{4} \beta_{\mathrm{d}}\left(\mathrm{I}_{\mathrm{i}}^{\mathrm{d}}\right)+\beta_{5}\left(\right.$ loan amount $\left._{\mathrm{i}}\right)+\beta_{6}\left(\right.$ income $\left._{\mathrm{i}}\right)+\varepsilon_{\mathrm{i}}$

where $\mathrm{I}_{\mathrm{i}}{ }^{\mathrm{d}}$ is an indicator function that takes the value 1 if household $I$ is of type 2,3 or 4 based on observable and unobservable information. There is a similar equation for $\rho$ :

Equation $11 \rho_{\mathrm{i}}=\gamma_{1}+\sum_{\mathrm{d}=2}^{4} \gamma_{\mathrm{d}}\left(\mathrm{I}_{\mathrm{i}}^{\mathrm{d}}\right)+\gamma_{5}\left(\right.$ loan amount $\left._{\mathrm{i}}\right)+\gamma_{6}\left(\right.$ income $\left._{\mathrm{i}}\right)+v_{\mathrm{i}}$

The models are estimated over loan origination years, 1995 to 1998 . This helps to make the regression results comparable to the previous ones. Estimating the coefficients for the alternative range of 1992 to 1995 does not change the results. The mortgage loan equations also condition on the maturity length $\left(\beta_{7}\right)$ and if the loan has a fixed interest rate $\left(\beta_{8}\right)$. Table 5 reports the coefficients and p-values from these models.

Note that $\gamma_{2}$ through $\gamma_{4}$ and $\beta_{2}$ through $\beta_{4}$ - the coefficients of interest - are significant with p-values less than .05 except for automobile's $\beta_{2}$ that has a p-value of 0.06 . The results from this estimation are most easily interpretable if predicted values of $r$ and $\rho$ are reported for each risk level, conditioning on certain values for income and the loan amount. These values for $r$ and $\rho$ are reported in Table 6 for an income of $\$ 45,000$ and average loan size for each loan type. While fixing income and loan size at different amounts will affect the estimates of $r$ and $\rho$, the coefficients on these independent variables is small enough that even extremely large changes have a negligible impact, and the relationships among the estimates are unchanged.

\section{i. Moral Hazard}

Note that in all cases $\rho\left(1+\mathrm{r}_{\mathrm{i}}\right) \leq 1$, evidence that the contracts are incentive compatible in the presence of moral hazard. Remarkably, the result again appears that $r_{4}<r_{2}$ for mortgages (with $\rho_{4}<\rho_{2}$ ) which is consistent with $\theta_{H}>\theta_{L}$. The null hypothesis that $r_{4}=r_{2}$ is easily rejected 
with a p-value of 0.002 . For automobile loans, while the point estimates continue to show that $r_{4}>r_{2}$, the null hypothesis that $r_{4}=r_{2}$ cannot be rejected. The p-value for this test is 0.83 , and the $95 \%$ confidence interval for the difference $r_{4}-r_{2}$ clearly includes many negative values. The null hypothesis that $\rho_{4}=\rho_{2}$ for automobiles also cannot be rejected, with a $p$-value of 0.55 . Overall, the results are consistent with the presence with moral hazard. Furthermore, as with the conditional mean results, the finding of $r_{4}<r_{2}$ for mortgages is only possible in this model if type $H$ have higher moral hazard than type $L$, and the effort frontiers bind.

\section{ii. Adverse Selection}

As in the conditional mean tests, for both loans, types 2 and 4 have a higher $r$ and $\rho$ than types 1 and 3, respectively. As case 3 explains, this is evidence of adverse selection in both the mortgage and automobile loan markets given the identifying assumptions. In the case of mortgages, while $\beta_{2}$ is significantly greater than zero, the null hypothesis that $\beta_{4}=\beta_{3}$ cannot be rejected. For the collateral model, $\gamma_{2}$ is significantly greater than zero, and here the null hypothesis that $\gamma_{4}=\gamma_{3}$ can be rejected with a $93 \%$ confidence level. For automobile loans, $\beta_{2}$ is significantly greater than zero ( $p$-value $=0.06$ ), but again the null hypothesis that $\beta_{4}=\beta_{3}$ cannot be rejected. Finally, $\gamma_{2}$ is significantly greater than zero, and the null hypothesis that $\gamma_{4}=\gamma_{3}$ can be rejected.

Wolak (1987) offers a multivariate one-sided hypothesis test to determine whether the absence of adverse selection can be rejected in each market. While the f-statistic is estimated in the usual way (given that the point estimates violate the null hypothesis in all cases), the distribution of the test statistic must be adjusted for the inequality constraints. These tests are 
reported in Table $7 .{ }^{13}$ Certainly, the evidence in support of adverse selection results is very robust to the empirical methodology.

\section{Another Test for Asymmetric Information}

Chiappori and Salanié (2000) describes a simple test for asymmetric information that does not rely on specific functional forms of the contract or assumptions on preferences or the nature of the equilibrium. Asymmetric information, taking the form of either adverse selection or ex-ante moral hazard, implies a positive correlation between two conditional distributions. To implement the test for the case of collateralized credit markets, interest rates, collateral and the propensity to be late on payments are all predicted.

Then, the residuals (or generalized residuals in the case of a probit) are calculated. Chiappori and Salanié define their test statistic:

Equation $12 W=\frac{\left(\sum_{i=1}^{n} \hat{\varepsilon}_{i} \hat{\eta}_{i}\right)^{2}}{\sum_{i=1}^{n} \hat{\varepsilon}_{i}^{2} \hat{\eta}_{i}^{2}}$

In this case $\hat{\varepsilon}$ might be the generalized residuals from the late payment probit, and $\hat{\eta}$ might be the residuals from the interest rate model. $W$ is distributed $\mathrm{X}(1)$ with the null hypothesis of no asymmetric information. If $W=0$ cannot be rejected, then there is no significant evidence that those with ex-post higher risk pay higher interest rates. Or, in the case equation:

\footnotetext{
${ }^{13}$ For a level .05 test with $p$ inequality constraints, the critical value is the solution in $x$ of the following
}

$$
.05=\sum_{\mathrm{k}=1}^{\mathrm{p}} \operatorname{Pr}\left[\mathrm{F}_{\mathrm{k}, \mathrm{N}-\mathrm{k}} \geq \mathrm{x} / \mathrm{k}\right] \mathrm{w}\left(\mathrm{p}, \mathrm{p}-\mathrm{k}, \mathrm{R} \Delta \mathrm{R}^{\prime}\right)
$$

where $\sigma^{2} \Delta$ is the variance/covariance matrix of the estimates, $R$ is the matrix of constraints of rank $p, N$ is the number of observations and $w(2,0, \Sigma)=1 / 2 \pi^{-1} \arccos \left(\rho_{12}\right)$ and $w(2,1, \Sigma)=1 / 2$. 
of collateral, that those with ex-post higher risk pledge less collateral. On the other hand, if $W=0$ can be rejected, there is evidence that observationally equivalent borrowers default more often when interest rates are higher and collateral is lower.

If we can rule out the possibility that some omitted variable is correlated with both dependent variables (with the correlations working in the right direction in both cases), rejecting $W=0$ is evidence of asymmetric information. The test is unable to determine whether this asymmetric information is adverse selection or moral hazard. For example, if the ex-post higher risk is associated with higher interest rates and lower collateral this may be due to adverse selection for all the reasons outlined in previous sections. However, without making assumptions on the nature of the equilibrium, one cannot rule out moral hazard. If contracts are assigned with some randomness (or due to some unrelated criteria), moral hazard could explain the how contracts with higher interest rates and lower collateral are associated with higher expost risk. While it is tricky to argue how this could come about with a well-functioning market, I cannot rule out the possibility with these simple tests of conditional correlation.

Even with these caveats, rejections of $W=0$ will bolster the evidence of asymmetric information in consumer loan markets. The approach will be to predict the propensity to make late payments as in Table 2, and then calculate the generalized residuals from this probit. Next, I predict mortgage interest rates and collateral ratios based on observables, including the predicted probability of making late payments, accounting for selection bias as described in Edelberg (2003). Residuals from these predictions are calculated, conditional on the dependent variable being observed. The results are reported in Table 8 . 
The results for mortgages show strong support for asymmetric information. The correlation between the late payment residual and the interest rate residual is positive, suggesting that higher ex-post risk is associated with higher interest rates. Additionally, the correlation between the late payment residual and the collateral residual is also positive, suggesting that higher ex-post risk is associated with lower collateral - and hence higher loanto-value ratios. Both of these relationships are significant in weighted and non-weighted test statistics. The complete lack of significance of the relationship between the collateral and interest rate residuals is encouraging. This suggests that important variables that are influential in contract determination have not been excluded.

The results for automobile rates are less conclusive. The correlations of the residuals have the expected signs, just as they do for first mortgages. Also, the test statistic for late payment/interest rate residuals is significant. However, the test statistic for late payment/collateral residuals is insignificant, making it more difficult to argue that this is evidence of asymmetric information. The significance of the relationship between late payment residuals and interest rate residuals may simply be due to an omitted variable. On the other hand, if an important omitted variable existed that predicted interest rates, one might expect that same variable to be important in the collateral model. Yet, there is a lack of significance of the relationship between the collateral and interest rate residuals (though indeed the unweighted p-value is 0.1). Again, this suggests that important variables that are influential in contract determination have not been excluded, suggesting that asymmetric information is driving the late payment/interest rate result. 


\section{Conclusion}

The results above have shown strong and robust evidence of adverse selection in a variety of empirical contexts. In both mortgage and automobile loan contracts, ex-post higher risk borrowers pledge less collateral and pay higher interest rates, while ex-post lower risk borrowers pledge more collateral and pay lower interest rates. Though the evidence for moral hazard is less conclusive, seemingly counter-intuitive results can be explained by higher risk borrowers being harder to induce into high effort. Overall, there are strong indications that moral hazard is broadly influential in the consumer loan contracts considered here. The results show that different households face heterogeneous interest rates and collateral requirements due to asymmetric information. A fully specified model of intertemporal household decisions should incorporate this heterogeneity. While the relationship between interest rates and default risk may not be monotonic due to the presence of moral hazard, future research will investigate the theoretical implications of interest rates as a function of financial and demographic characteristics.

Indeed, these results are only a starting point and suggest a number of other interesting extensions. For example, the model assumes that all households have the same utility function. However, two financially similar households may have different utility functions and thus different levels of risk aversion. The more risk adverse household should be willing to accept a greater increase in the interest rate for an equal reduction in collateral than the less risk adverse household. The Survey of Consumer Finances contains a set of questions that aim to measure risk aversion of individual households. These measures could be used to estimate this additional testable implication from the model. 
Furthermore, a change in market efficiency should affect the role of unobservables. For example, if markets are becoming more efficient over time, unobservables should lose some of their significance in determining loan terms. This model could be adapted to assess the effects of varying degrees of asymmetric information in order to test this hypothesis. In this same vein, this framework may give some insight into loan market participation. The greater importance of asymmetric information leads to higher costs of borrowing - both in the interest rate and in collateral requirements. Perhaps these costs can be linked with the extent to which potential borrowers are discouraged from applying.

Finally, a more useful way of testing asymmetric information is to look at the terms in a household's entire loan portfolio. Rather than considering specific loans in turn, such as mortgage and automobile loans, we should look at the interest rates and pledged collateral across all loans. If priority in bankruptcy proceedings is kept in mind, this would give a better picture of how households are sorted by lenders. For example, ex-post low risk households may have virtually no non-collateralized debt while ex-post high risk households may have very little collateralized debt. By only looking at collateralized loans, we are potentially missing an important segment of the population. 


\section{References}

Akerlof, G. A., "The Market for 'Lemons': Qualitative Uncertainty and the Market Mechanism," Quarterly Journal of Economics, 84, August, 1970, pages 488-500.

Altman, Daniel, David M. Cutler, and Richard J. Zeckhauser, "Adverse Selection and Adverse Retention," American Economic Review, 88(2), May, 1998, pages 122-26.

Ausubel, Lawrence, “Adverse Selection in the Credit Card Market,” Working Paper, 1999.

Bester, H, "The Role of Collateral in Credit Markets with Imperfect Information," European Economic Review, 31, 1987, pages 887-899.

Bester, H, "Screening versus Rationing in Credit Markets with Imperfect Information," American Economic Review, 75, 1985, pages 850-855.

Bond, Eric W., "A Direct Test of the 'Lemons' Model: The Market for Used Pickup Trucks," American Economic Review, 72(4), September, 1982, pages 836-40.

Calem, Paul S. and Loretta J. Mester, "Consumer Behavior and the Stickiness of Credit-Card Interest Rates,” American Economic Review, 85(5), December, 1995, pages 1327-36.

Chan, Y. S. and A. Thakor, "Collateral and Competitive Equilibrium with Moral Hazard and Private Information,” Journal of Finance, 42, June 1987, pages 345-363.

Chassagnon, A and Pierre-André Chiappori, "Insurance under Moral Hazard and Adverse Selection: the Case of Pure Competition,” Working Paper, 1996.

Chiappori, Pierre-André and Bernard Salanié, "Testing for Asymmetric Information in Insurance Markets,” Journal of Political Economy; 108(1), January 2000, pages 56-78.

Dubey, Pradeep and John Geanakoplos, "Signaling and Default: Rothschild-Stiglitz Reconsidered," Cowles Foundation Discussion Paper, no. 1305, May, 2001.

Edelberg, Wendy, "Using Observable Default Risk to Explain Interest Rate Heterogeneity in Consumer Loan Markets," Working Paper, June 2003.

Fay, Scott, Erik Hurst and Michelle White, “The Bankruptcy Decision: Does Stigma Matter?" Working Paper, January 1998.

Genesove, David, “Adverse Selection in the Wholesale Used Car Market," Journal of Political Economy, 101(4), August, 1993, pages 644-65.

Igawa, Kazuhiro and George Kanatas, "Asymmetric Information, Collateral, and Moral Hazard," Journal of Financial and Quantitative Analysis; 25(4), December 1990, pages 469-489.

Jones, Lawrence, "Deficiency Judgments and the Exercise of the Default Option in Home Mortgage Loans," Journal of Law and Economics, vol. XXXVI, April, 1993, pages 115-138. 
Mirrlees, J A, "The Theory of Moral Hazard and Unobservable Behaviour: Part I," Review of Economic Studies, 66 (1), January, 1999, pages 3-21.

Rothschild, Michael and Joseph E. Stiglitz, "Equilibrium in Competitive Insurance Markets: An Essay on the Economics of Imperfect Information," Quarterly Journal of Economics, 90(4), November, 1976, pages 630-49.

Stiglitz, J. and A. Weiss, "Credit Rationing in Markets with Imperfect Information," American Economic Review; 71(3), June 1981, pages 393-410.

Sullivan, Teresa, Elizabeth Warren and Jay Westbrook, The Fragile Middle Class, Yale University Press, New Haven, 2001.

Wolak, Frank, “An Exact Test for Multiple Inequality and Equality Constraints in the Linear Regression Model," Journal of the American Statistical Association, 82(399), September 1987, pages 782-793. 


\section{Tables and Figures}

\section{Table 1. Distribution of Mortgages and Automobile Rates}

\begin{tabular}{|l|l|l|}
\hline & $\mathbf{1}^{\text {st }}$ Mortgage Rates & Automobile Rates \\
\hline $1^{\text {st }}$ Percentile & $5.8 \%$ & 1.9 \\
\hline $10 \%$ & 6.75 & 6.5 \\
\hline $25 \%$ & 7.0 & 7.9 \\
\hline $50 \%$ & 7.7 & 9.0 \\
\hline $75 \%$ & 8.5 & 12.0 \\
\hline $90 \%$ & 10.0 & 17.9 \\
\hline $99 \%$ & 13.2 & 25.0 \\
\hline Range & $2.75-18.0$ & $0.9-35.0$ \\
\hline Mean & 8.0 & 10.3 \\
\hline Standard Deviation & 1.47 & 4.45 \\
\hline
\end{tabular}

Interest rates are from loan origination years 1995 to 1998 
Table 2. Late Payment Indicator Probit

\begin{tabular}{|c|c|c|c|}
\hline & Coefficient & Robust Standard Error & p-value \\
\hline 1989 & 0.724 & 0.407 & 0.08 \\
\hline 1992 & -0.077 & 0.173 & 0.66 \\
\hline 1995 & -0.399 & 0.135 & 0.00 \\
\hline 1998 & -0.106 & 0.142 & 0.46 \\
\hline Age & 0.026 & 0.009 & 0.00 \\
\hline Age Squared & $-4.47 \mathrm{E}-04$ & $9.81 \mathrm{E}-05$ & 0.00 \\
\hline No checking account & 0.346 & 0.058 & 0.00 \\
\hline Ln (Income) & 0.014 & 0.007 & 0.03 \\
\hline $\mathrm{x} 1989$ & -0.212 & 0.039 & 0.00 \\
\hline x1992 & -0.038 & 0.015 & 0.01 \\
\hline $\mathrm{x} 1995$ & 0.006 & 0.011 & 0.58 \\
\hline $\mathrm{x} 1998$ & -0.025 & 0.012 & 0.04 \\
\hline Self Employed & -0.032 & 0.094 & 0.73 \\
\hline x1989 & 0.198 & 0.161 & 0.22 \\
\hline $\mathrm{x} 1992$ & 0.285 & 0.145 & 0.05 \\
\hline $\mathrm{x} 1995$ & 0.047 & 0.153 & 0.76 \\
\hline $\mathrm{x} 1998$ & 0.247 & 0.153 & 0.11 \\
\hline Home ownership & -0.097 & 0.072 & 0.18 \\
\hline x1989 & -0.188 & 0.123 & 0.12 \\
\hline $\mathrm{x} 1992$ & -0.229 & 0.112 & 0.04 \\
\hline $\mathrm{x} 1995$ & -0.206 & 0.107 & 0.05 \\
\hline x1998 & -0.059 & 0.113 & 0.60 \\
\hline NC Debt/Income $>2.5$ & 0.370 & 0.123 & 0.00 \\
\hline Positive Net worth & $-7.00 \mathrm{E}-08$ & $4.66 \mathrm{E}-08$ & 0.13 \\
\hline x1989 & $6.18 \mathrm{E}-08$ & $4.75 \mathrm{E}-08$ & 0.19 \\
\hline x1992 & 7.41E-09 & $5.65 \mathrm{E}-08$ & 0.90 \\
\hline $\mathrm{x} 1995$ & $-6.05 \mathrm{E}-08$ & $9.11 \mathrm{E}-08$ & 0.51 \\
\hline x1998 & $-5085 \mathrm{E}-07$ & $2.55 \mathrm{E}-07$ & 0.02 \\
\hline Non-collateralized Debt & $1.40 \mathrm{E}-07$ & $1.10 \mathrm{E}-07$ & 0.20 \\
\hline Unemployed & 0.188 & 0.102 & 0.07 \\
\hline $\mathrm{x} 1989$ & 0.238 & 0.192 & 0.22 \\
\hline $\mathrm{x} 1992$ & -0.533 & 0.216 & 0.01 \\
\hline $\mathrm{x} 1995$ & -0.271 & 0.208 & 0.19 \\
\hline $\mathrm{x} 1998$ & 0.040 & 0.188 & 0.83 \\
\hline Black & 0.484 & 0.086 & 0.00 \\
\hline $\mathrm{x} 1989$ & -0.107 & 0.153 & 0.10 \\
\hline $\mathrm{x} 1992$ & -0.259 & 0.155 & 0.10 \\
\hline $\mathrm{x} 1995$ & -0.247 & 0.145 & 0.09 \\
\hline $\mathrm{x} 1998$ & -0.183 & 0.136 & 0.18 \\
\hline Education Class & -0.091 & 0.016 & 0.00 \\
\hline Single Parent & 0.122 & 0.053 & 0.02 \\
\hline Constant & -1.234 & 0.203 & 0.00 \\
\hline
\end{tabular}

Probit portion of selection model is excluded for brevity. See Edelberg (2003). 
Table 3. Predicted Probability of Late Payments

\begin{tabular}{|l|l|}
\hline $\mathbf{1}^{\text {st }}$ Percentile & 0.001 \\
\hline $\mathbf{1 0} \%$ & 0.010 \\
\hline $\mathbf{2 5 \%}$ & 0.026 \\
\hline $\mathbf{5 0} \%$ & 0.056 \\
\hline $\mathbf{7 5 \%}$ & 0.118 \\
\hline $\mathbf{9 0 \%}$ & 0.207 \\
\hline $\mathbf{9 9 \%}$ & 0.479 \\
\hline Range & $0.000-0.99$ \\
\hline Mean & 0.089 \\
\hline Standard Deviation & 0.098 \\
\hline
\end{tabular}

Table 4. Conditional Mean Tests, Interest Rates and Collateral

\begin{tabular}{|l|l|l|}
\hline & r & \multicolumn{1}{l|}{$\rho$} \\
\hline First Mortgage Loans & \multicolumn{2}{|l|}{} \\
\hline L - type 1 (bin size: 514) & $7.44(.05)$ & $0.54(.03)$ \\
\hline L - type 2 (7) & $10.91(.91)$ & $0.84(.05)$ \\
\hline H - type 3 (494) & $8.10(.07)$ & $0.69(.01)$ \\
\hline H - type 4 (27) & $8.30(.25)$ & $0.75(.05)$ \\
\hline Auto Loans & \multicolumn{2}{|l|}{} \\
\hline L - type 1 (331) & $9.01(.19)$ & $0.63(.02)$ \\
\hline L - type 2 (5) & $11.70(1.39)$ & $0.86(.15)$ \\
\hline H - type 3 (259) & $11.32(.29)$ & $0.80(.02)$ \\
\hline H - type 4 (29) & $12.09(.99)$ & $0.96(.11)$ \\
\hline
\end{tabular}

Standard errors in parenthesis

Table 5. Regression Estimates, Coefficients and P-values

\begin{tabular}{|c|c|c|}
\hline \multicolumn{3}{|c|}{ Interest Rates (r) } \\
\hline & Mortgage Loans & Auto Loans \\
\hline$\overline{\beta_{1}}$ & $7.63(.00)$ & $9.55(.00)$ \\
\hline$\beta_{2}$ & $3.39(.00)$ & $2.40(.06)$ \\
\hline$\beta_{3}$ & $0.59(.00)$ & $2.10(.00)$ \\
\hline$\beta_{4}$ & $0.74(.00)$ & $2.75(.00)$ \\
\hline$\beta_{5}$ & $-1.72 \mathrm{e}-07(.15)$ & $-.00002(.38)$ \\
\hline$\beta_{6}$ & $-6.05 e-08(.09)$ & $-1.09 \mathrm{e}-06(.08)$ \\
\hline$\beta_{7}$ & $-.011(.04)$ & na \\
\hline$\beta_{8}$ & $0.035(.18)$ & na \\
\hline
\end{tabular}

\begin{tabular}{|c|c|c|}
\hline \multicolumn{3}{|c|}{ Collateral Ratio ( $\rho)$} \\
\hline & Mortgage Loans & Auto Rates \\
\hline$\gamma_{1}$ & $0.28(.00)$ & $0.45(.00)$ \\
\hline$\gamma_{2}$ & $0.33(.00)$ & $0.31(.02)$ \\
\hline$\gamma_{3}$ & $0.20(.00)$ & $0.20(.00)$ \\
\hline$\gamma_{4}$ & $0.30(.00)$ & $0.41(.02)$ \\
\hline$\gamma_{5}$ & $6.01 \mathrm{e}-07(.05)$ & $.00001(.00)$ \\
\hline$\gamma_{6}$ & $-1.18 \mathrm{e}-07(.03)$ & $-3.65 \mathrm{e}-07(.00)$ \\
\hline$\gamma_{7}$ & $0.004(.00)$ & na \\
\hline$\gamma_{8}$ & $0.012(.10)$ & na \\
\hline
\end{tabular}


Table 6. Parametric Tests, Interest Rates and Collateral

\begin{tabular}{|l|l|l|}
\hline & r & p \\
\hline First Mortgage Loans & \multicolumn{2}{|l|}{} \\
\hline L - type 1 & 7.47 & 0.48 \\
\hline L - type 2 & 10.87 & 0.82 \\
\hline H - type 3 & 8.07 & 0.69 \\
\hline H - type 4 & 8.21 & 0.79 \\
\hline Auto Loans & \multicolumn{2}{|l|}{} \\
\hline L - type 1 & 9.41 & 0.48 \\
\hline L - type 2 & 11.81 & 0.79 \\
\hline H - type 1 & 11.51 & 0.68 \\
\hline H - type 2 & 12.16 & 0.89 \\
\hline
\end{tabular}

Table 7. One-Sided Multivariate F-tests for Adverse Selection

\section{Conditional Mean Models}

\begin{tabular}{|l|l|}
\hline $\mathbf{1}^{\text {st }}$ Mortgage & Automobile Loans \\
\hline
\end{tabular}

\begin{tabular}{|l|l|l|}
\hline $\mathrm{H}_{0}: \mathrm{r}_{2} \leq \mathrm{r}_{1} \& \mathrm{r}_{4} \leq \mathrm{r}_{3}$ & 15.01 & 4.23 \\
\hline $\mathrm{H}_{0}: \rho_{2} \geq \rho_{1} \& \rho_{4} \geq \rho_{3}$ & 32.42 & 4.22 \\
\hline
\end{tabular}

\section{Regression Models}

\begin{tabular}{|l|l|l|}
\hline $\mathrm{H}_{0}: \beta_{2} \leq 0 \& \beta_{4} \leq \beta_{3}$ & 8.40 & 1.94 \\
\hline $\mathrm{H}_{0}: \gamma_{2} \geq 0 \& \gamma_{4} \geq \gamma_{3}$ & 20.73 & 4.54 \\
\hline
\end{tabular}

95\% confidence level critical value: $4.23 *$

*While the critical value as derived in Wolak (1987) is slightly different in each case, the similarity of certain elements of $\mathrm{R}\left(\mathrm{X}^{\prime} \mathrm{X}\right)^{-1} \mathrm{R}^{\prime}$ render the critical values in the range 4.234 to 4.235 .

\section{Table 8. An Additional Test for Adverse Selection}

\begin{tabular}{|l|l|l|l|}
\hline Residuals from Models: & Late, $\mathbf{r}$ & Late, $\boldsymbol{\rho}$ & r, $\boldsymbol{\rho}$ \\
\hline Mortgage Rate & & & \\
\hline Correlation of residuals & 0.0436 & 0.0208 & 0.0072 \\
\hline p-value of W & 0.00 & 0.02 & 0.75 \\
\hline p-value of W, weighted* & 0.04 & 0.07 & 0.85 \\
\hline Automobile Rates & & & \\
\hline Correlation of residuals & 0.0639 & 0.0010 & 0.0122 \\
\hline p-value of W & 0.00 & 0.35 & 0.10 \\
\hline p-value of W, weighted* & 0.00 & 0.64 & 0.22 \\
\hline
\end{tabular}

* Survey weights from the SCF are used in calculating $\mathrm{W}$. 
Figure 1. Moral Hazard

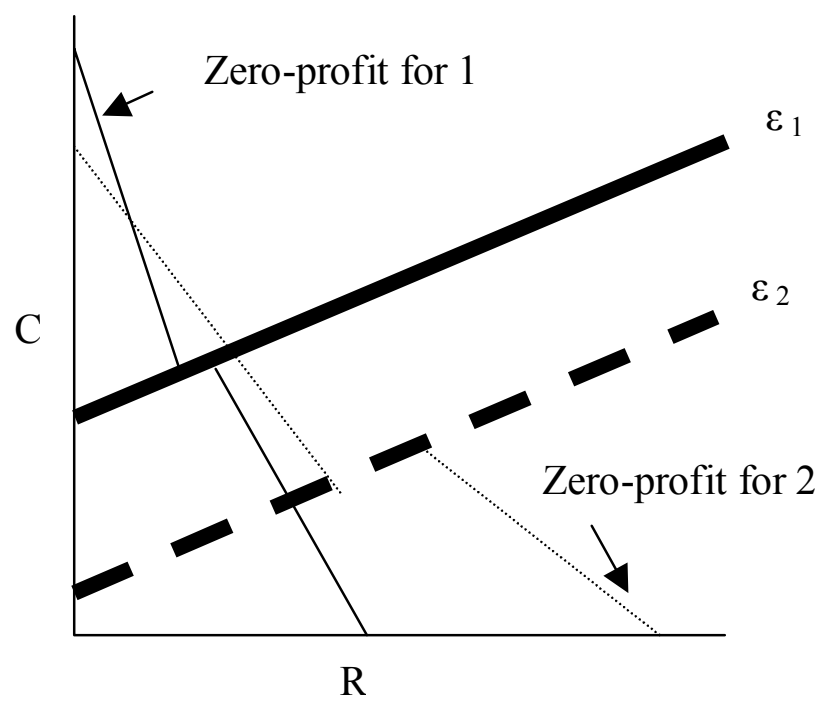

Figure 2. Adverse Selection with No Moral Hazard

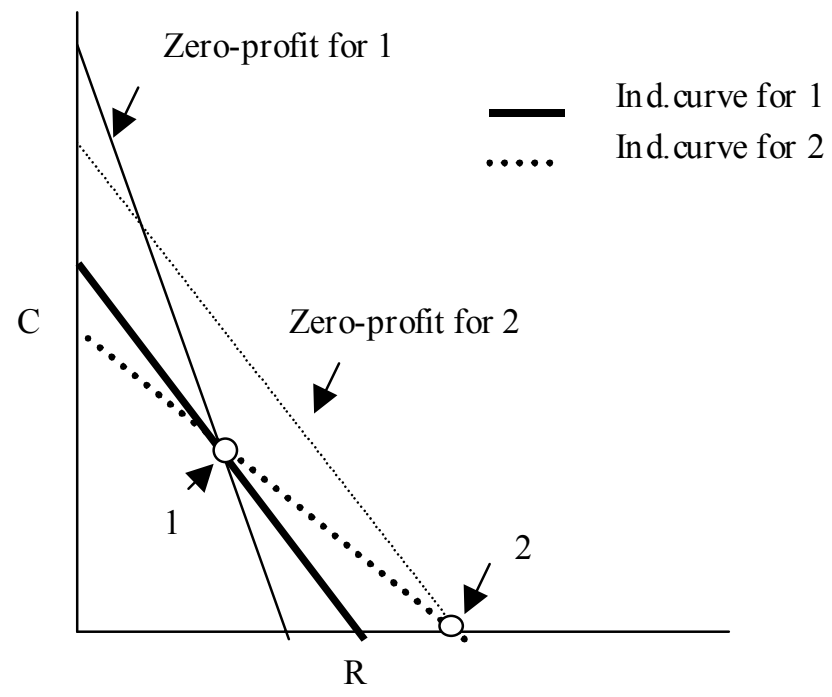


Figure 3. Separating Equilibria with Induced High Effort

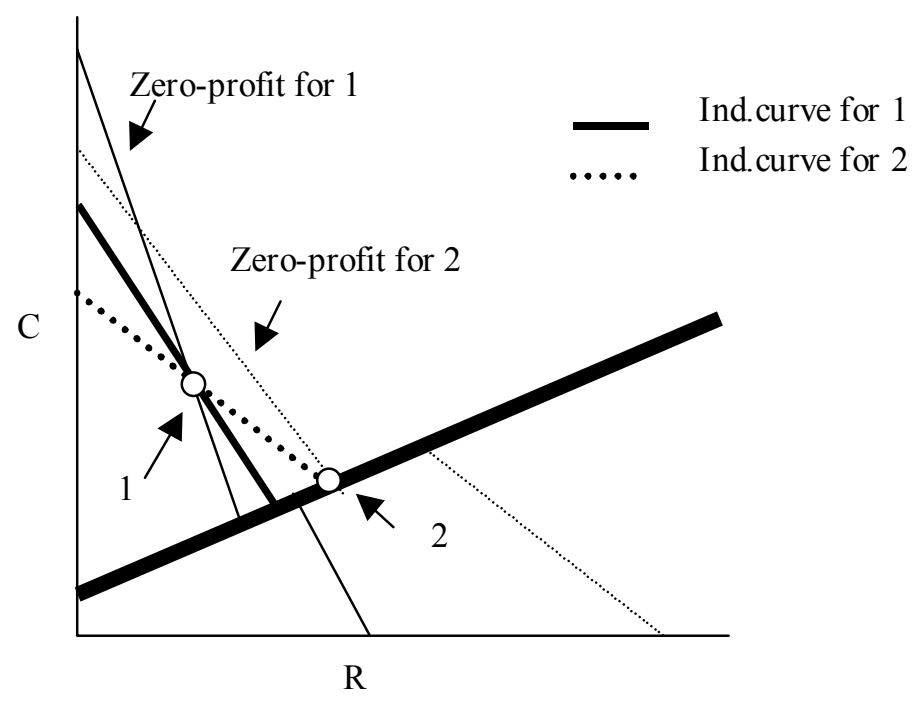

Figure 4. Possible Equilibria with Lower Cost of Effort for Group L

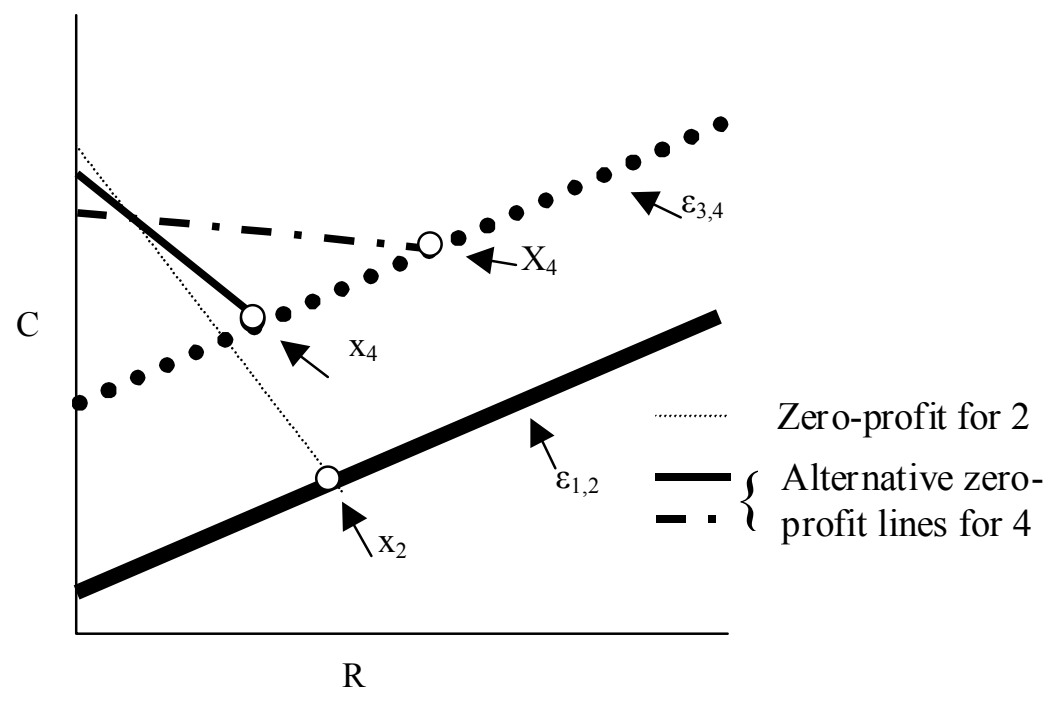


Figure 5. The Case of No Adverse Selection with Effort

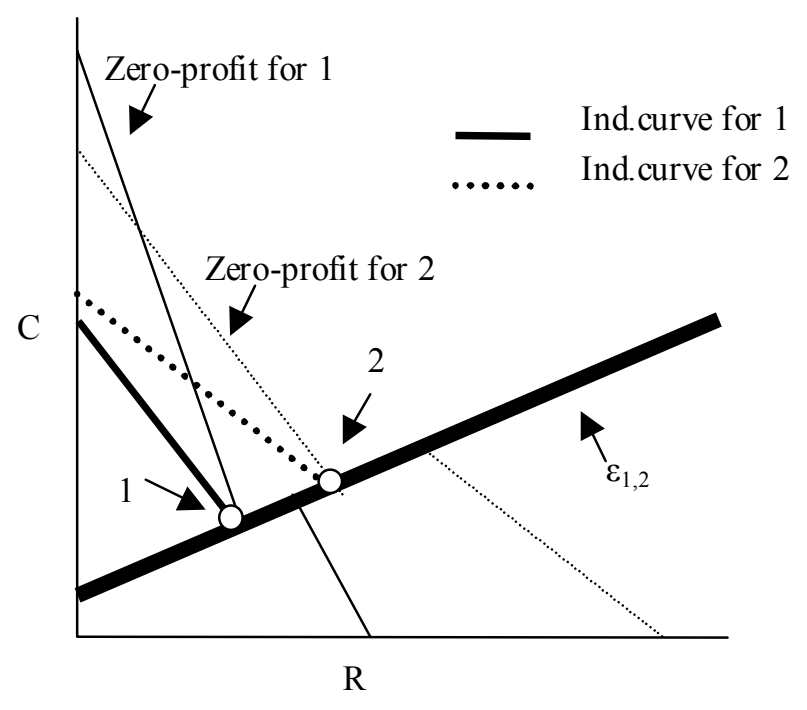

